\title{
Intentionalism and the Problem OF The ObJect of Perception ${ }^{1}$
}

\author{
Karla Chediak ${ }^{2}$
}

\begin{abstract}
In this paper, I intend to review the intentionalist account of perceptual experience in order to deal with some difficulties that it faces in adequately specifying the nature and object of perceptual experience. My aim is to show that it is possible for the intentionalists to incorporate the disjunctivist thesis that the object of perception is part of perceptual experiences, without renouncing the common factor principle. I argue that, in order to do this, it is necessary to engage with the concept of biological function and to review the concept of a perceptual object.
\end{abstract}

KEYWORDS: Perceptual intentionalism, intentional object, hallucination, disjunctivism, biological function.

\section{INTRODUCTION}

In this paper, I intend to review the intentionalist account of perceptual experience in order to deal with Michael Martin's disjunctivist criticism, in which he argues that intentionalism cannot give a satisfactory explanation of perceptual experience. According to that criticism, perceptual intentionalism has a difficulty in adequately specifying the nature of a perceptual object.

My aim is to show that intentionalists do not need to appeal to an intentional object in order to sustain the intentionality of mental states and their relational character. I think that it is possible for intentionalists to incorporate the disjunctivist thesis that the object of perception is necessarily part of perceptual experiences without renouncing the common factor principle. I argue that to do that it is necessary to engage with the concept of biological function and to review the concept of a perceptual object.

The apparent difficulty of specifying the nature of a perceptual object in intentionalism is particularly manifested when we consider hallucinatory experiences, for two basic reasons. Firstly, perceptual intentionalists accept

\footnotetext{
${ }^{1}$ http://dx.doi.org/10.1590/S0101-31732016000200005

${ }^{2}$ Professora Associada do Departamento de Filosofia da UERJ/CNPq. E-mil: kachediak@gmail.com.
} 
the common factor principle, and disjunctivists do not. The common factor principle states that veridical, illusory, and hallucinatory experiences have the same content or nature. This principle marks one of the main differences between intentionalism and disjunctivism. In general, disjunctivists adopt the view that there is no common perceptual content between perceptual experiences of one object and another, or between a hallucinatory or illusory experience and a perceptual experience, even if the perceiver cannot discriminate one experience from the other

Secondly, intentionalism accepts that the phenomenal character of experiences, at least partially, specifies the representational content of perception. As Tim Crane (2006, p.133), points out: “[...] it seems possible for there to be an experience which seems just like a perception of a real mindindependent object but where there is no real mind-independent object being perceived". The consequence, he stresses, is either to postulate the existence of sense-data or to deny that perception is a relation. According to Crane, representationalism 3 is associated with the second alternative, because the object can be represented whether or not it exists. Michael Martin (2002b, p.402), states a similar view: "According to the intentional approach we should not suppose that we have to understand the phenomenological character of perceptual experience in relational terms".

However, perceptual intentionalism requires a relation to an object 4 . One of the most important theses of intentionalism is aboutness: that is, the assumption that every mental state is about something, and has an object.

Moreover, intentionalism is also committed to the thesis that intentional states are corrigible. Disjunctivists can argue that perceptual states are not corrigible, and that perceptual illusions and hallucinations are similar to perceptual experiences, however, in this case, they would not be perceptions in a proper sense. In general, intentionalists do not agree with that conception, and although they do not have difficulty explaining veridical and illusory experiences, they tackle this problem through explaining hallucinatory experiences. In veridical experiences, the intentional content is about the suitable external object that is presented in the experience. In

\footnotetext{
${ }^{3}$ Like Tim Crane in his paper Intentionalism (2007), I am not considering any distinction between intentionalism and representationalism in this paper.

${ }^{4} \mathrm{I}$ am using the term "object" as a general term to designate any perceived entity as properties of an object, objects, or events. Objects are presented in accurate and inaccurate experiences, but not in hallucinatory experiences.
} 
illusory experiences, when the perceptual content is not related to the suitable object, there is still an external object related to the individual.

In a hallucinatory experience, there is no external object that is related to the individual. However, it is argued that intentionalism requires the content of an experience always to be directed to an object. Therefore, the problem is how to maintain that the content of hallucinatory experiences is intentional. It does not seem reasonable to say that content is intentional without assuming that it is directed to an object. However, if there is no current object, it seems that we have to appeal to another kind of object.

\section{INTENTIONALISM AND THE INTENTIONAL OBJECT}

To avoid the claim that hallucinatory experiences are intentional without having an object, intentionalists could appeal to the concept of an "intentional object". The important feature of these objects is that they do not need exist in order to be seen as objects. Intentional objects exist only if they are actual objects that are presented in experiences. In hallucinatory experiences, where there is no actual external object, the object is only intentional. Consequently, perceptual experience in these cases is non-veridical. This is because the intentional object is perceived as an external object.

The notion of intentional objects could be a solution for the problem of how to determine the object of hallucinatory experiences. However, explaining the nature of intentional objects is more difficult. They cannot be mental objects, since mental objects are internal. They cannot be phenomenal objects, because, in intentionalism, phenomenal experiences are presentation of external objects. Intentionalism is committed to the thesis that perceptual experience is a relation to the properties of the external world and not to the properties of the experience itself (HARMAN, 1990, p.39).

Frank Jackson (1977, quoted in HARMAN, 1990, p. 37) defended the existence of mental objects ${ }^{5}$, saying that it would be more reasonable to suppose that a person is conscious of something mental than to suppose that she is conscious of something that does not exist. On the contrary, Gilbert Harman, has claimed that "From the fact that there is no Fountain of Youth, it does not follow that Ponce de Leon was searching for something mental." (HARMAN, 1990, p.36). Therefore, Harman argues, it is better to suppose

${ }^{5}$ JACKSON, F. Perception: a representative theory. Cambridge: Cambridge Univ. Press, 1977. 
that he was looking for something non-existent than for something merely mental, and the same should apply to visual experiences. In cases where there is no actual object, we could say that one did not see any mental object or any external object. The correlate of the visual content of his experience would be an intentional object.

Tim Crane has argued that intentional object is the central notion of intentionalism. Although his reflections about intentionalism mainly focus on thoughts, he observes that he does not limit its employment only to thoughts. The notion of the intentional object applies to other mental states, including hopes, desires, fears, senses and perceptual experiences: "[...] all these states have objects, just as episodes of thinking (in strict sense) do." (CRANE, 2013, p. 90). According to Crane, the intentional object is characterized by the fail of existential generalization. This means that for something to be intentional object, it does not need to exist or be determinate, and has neither a logical nor an ontological status. In fact, it has no nature.

In his book Elements of mind (2001), Crane says that this concept of non-existent intentional object is not substantial, but schematic. Schematic objects, in contrast to substantial ones do not have a nature. They can be characterized in analogy with Anscombe's grammatical use of "object", which is an object in the sense that it plays a role in a sentence. However, Crane (2001, p.22) emphasizes that an intentional object cannot be grammatically characterized, because there are intentional states that are not propositional, and the schematic idea of an intentional object applies to all intentional states.

In his article "Intentionalism" (2007), Crane does not refer to this distinction between the substantial and schematic conception of intentional objects. Instead, he characterizes intentional objects by the notion of "selftranscendence", meaning by this that they are not immanent to the intentional states even when they are non-existent. He explains why intentional objects must transcend intentional states by arguing that it is not essential for an intentional object to be the object of any particular state of mind. An intentional object is not sufficient to individuate a state of mind, that is, different states of mind might have the same intentional object (CRANE, 2007, p. 5).

In his most recent book, The objects of thought (2013), Crane does not refer to the schematic or the transcendent ideas of intentional objects. He simply stresses that intentional objects have no ontological category, because they are neither entities nor quasi-entities (CRANE, 2013, p. 95). He thinks 
that the term "aboutness", essential to intentionalism, requires, by definition, the notion of an intentional object. He also argues that, because we can think about things that do not exist, there are non-existent intentional objects (CRANE, 2013, p. 90).

For the purpose of this paper, I will consider Crane's conception of an intentional object as presented in his paper Intentionalism, according to which every intentional state involves four central concepts: (i) the intentional object, whether real or unreal; (ii) the character of the transcendence of the intentional object; (iii) the intentional mode; and (iv) the intentional content (CRANE, 2007, p. 2-6). The intentional object is the central element because the meaning of other elements depends on it. Firstly, transcendence or immanence is a feature of the intentional object. Secondly, the intentional mode means that the intentional object can be the object of different modes, such as belief and desire. Finally, the intentional content means that the object can be presented in different ways, even when the mode is the same (CRANE, 2007, p. 5).

I think that there is a difficulty with Crane's conception of intentional object when it is applied to perceptual states, especially in relation to cases where there is no real object. According to Crane, in such cases, there are "mere intentional objects" which are not immanent in intentional states (CRANE, 2007, p. 5). In his articles, Crane proposes to consider the nonexistent intentional object either as schematic (2001) or by its transcendence of intentional states (2007). I think that the idea of an intentional object as schematic might work in terms of linguistically structured thoughts, but I do not see how appealing to it can help to explain an experiential states when there is no object, neither how it could help to explain the fundamental problem of distinguishing these states from similar ones where a real object is causing the experience.

The same difficult is present if we try to appeal to the notion of transcendence. We may ask why the non-existent intentional object cannot be immanent to the experiential state. According to Crane, this is because an intentional object is not part of any particular mental state, as different states of mind can have the same intentional object. This can be correct in respect to veridical experiences, because it is possible to perceive external objects accurately in different ways, but it is not obvious that different hallucinatory experiences can have the same intentional object. 


\section{INTENTIONALISM AND THE RELATIONAL VIEW}

It seems to me that, in such cases, the intentional object should either be seen as something that is posed and determined by the intentional content, or it should be argued that there is no object at all. Crane does not accept this last option, arguing that the intentional object is a requirement of fact, since we can think of things that do not exist. He argues that appealing to the intentional object is the only way to explain cases where the same intentional state is present, whether or not their intentional object exists. The consequence, he stresses, is that intentionalism cannot be a relational view of perception, since the intentional state can be the same with or without the object: "I call the non-relational, representational conception of experience intentionalism." (CRANE, 2006, p.135).

I believe that it is possible to make intentionalism compatible with a relational view of perception, but we have to discuss whether it is really necessary to maintain the concept of the intentional object. In fact, if the intentional object is neither internal and mental nor external and real, and it is not determined by the content, because it transcends intentional states, I do not think that it is a very helpful concept in explaining our mental states.

In this respect, I agree with Michael Martin when he says that the appeal to intentional objects does not place the intentionalist view in a better position than the sense-datum view of perception (MARTIN, 2002b, p.385, note 14). However, I think that it is enough for intentionalists to conceive intentional states as having two basic properties - aboutness and corrigibility - without accepting that there is an intentional object. In fact, the notions of content and of real objects are sufficient to ground these two properties of intentional states, as Tyle Burge has rightly observed ${ }^{6}$. Aboutness can be seen as a characteristic of the intentional content, which can either be satisfied or not.

By definition, hallucinatory experiences have no external object or current objects causing the experiences, but they can be thought of as intentional states because they have intentional contents. Intentionalists need to sustain this notion. They also have to explain how a hallucinatory

\footnotetext{
6 "Confused use of the term "about" is one of the most common bases for confusion regarding representation. Confusion resides in postulating a representatum (or "object" of representation, or "intentional object") wherever talk of representation is meaningful. Grammatical object and subjectmatter object are then frequently confused. Representation that involves representation failure, lack of representata, is a function of a state, event, or representational content -not a relation to a subject matter." (BURGE, 2010, p. 44, note 18).
} 
experience can be a perceptual experience, if no object is presented to the perceiver, and how the same content can be present in cases where there is an object and where there is not.

It is due to these difficulties of the intentional theory of perception that some philosophers, including Martin, argue that we cannot say that perceptual intentionalism is a relational conception of perceptual experience. Martin says that intentionalism can, at best, be thought as a "quasi-relational" theory, since experiences might or might not be presentations of an object. In cases of hallucinatory experience, they are not presentations of an object. He affirms that part of the difficulty of relating intentionalism to a relational view of perception consists in its commitment to the thesis that accurate and inaccurate perceptual experiences can be the same mental states, and can have the same nature (MARTIN, 2002b, p. 402).

Contrary to Martin, I contend that if it is right to think that the phenomenal character of perceptual experiences characterizes at least part of the content of these experiences, then two experiences, one veridical and the other non-veridical, with the same phenomenal character, can have the same phenomenal content. There are two ways to argue against this contention. It could either be argued that the content of perceptual experience contains more than the phenomenal appearance, or that the phenomenal appearance includes the object itself. Martin proposes that the object itself should be included in the phenomenological appearance when he says: "[... an experience could be entirely qualitatively identical with another experience involving a distinct object and yet still differ in its phenomenal nature solely in this respect" (MARTIN, 2002a, p. 13). I believe that Martin's view here difficult to accept. It seems natural to think that the phenomenal character of experience is what appears to the perceiver and everything that does not appear it is not part of the phenomenal content.

However, I think that it is possible for intentionalists to at least partially accept the disjunctivist view about perception without assuming Martin's view. I think that similar experiences, one with an external object and another without an object, should not be thought of as the same kind of experience, even if they have the same phenomenal character. ${ }^{7}$ Only an experience that

\footnotetext{
${ }^{7}$ It is possible to question whether considering two experiences, one with an object and the other without an object as distinct from each other really makes an important difference in the explanation of perceptual experiences. I think that it does, because it helps to clarify the conceptual understanding of what happens during perceptual experiences.
} 
is caused by a current object should be considered perception in the proper sense; experiences without objects would be hallucinatory experiences, which are a different kind of experience. Therefore, I think that it is possible to have different experiences with the same kind of phenomenal content. Perceptual experiences involve the environment as part of the experience. This is why the mental state during perception always informs the subject about the environment. Perceptual experiences are relational states, where the object must be present and must cause the experience.

According to these criteria, hallucinatory experiences are not relational in the same sense as perceptual experiences. However, if they both have the same phenomenal content, then it is possible to conclude that the content specifies the phenomenological character of experience, but it does not determine the nature of a perceptual experience. Thereby, I believe that it is possible to maintain the thesis that the content of a perceptual experience can be the same in both veridical and non-veridical experiences without accepting that experiences are the same type of experience whether or not an object is present. Perceptual experiences involve the environment, they occur when we really perceive something, and we perceive something when there is an external object to be perceived.

If hallucinatory, illusory and veridical experiences are all perceptual experiences, the distinction between them is only a difference of accuracy. However, this difference does not seem sufficient to grasp the true relational character of perceptual experiences.

For instance, suppose there are two experiences with exactly the same appearance that appear to have the same phenomenal content. The problem that disjunctivists have noted is how the content can represent the external object, if it sometimes represents the object wrongly, and if there is sometimes no object represented. Even disjunctivists must agree that, if we consider only the content, we cannot really discriminate between experiences or determine which object is causing the experience, or even determine if there is one object. However, they argue that this fact does not imply that their contents is either the same or has the same nature. I think that it is more reasonable to say that the content has the same nature, but that it does not originate from the same experience.

Intentionalists who would not like to adopt an indirect view or a non-relational view of perception should partially accept the disjunctivist view of perception. An indirect view of perception does not provide a good 
explanation about the relation between the perceptual content and the object perceived.

However, intentionalists cannot accept the disjunctivist rejection of the common factor principle and the intentional character of hallucinatory mental states. Therefore, intentionalists should hold that the content of perceptual experience is dependent on the external object, while accepting the common factor principle. I think that it is possible to defend this view by adopting a physicalist view of perception and resorting to the concept of biological function.

\section{Perceptual intentionalism and the Concept of Function}

The intentionalist's conception of the object should be different from disjunctivist's conception of the object. To disjunctivists, the object that is being considered is only the object that is currently being perceived. But intentionalists cannot give a good explanation about the relation between the phenomenal properties of experience -its content- and the represented object, considering that the term "object" refers only to the current object of perception.

Intentionalists should also assume that the phenomenal character that appears to the individual when he has either a perceptual experience or a hallucinatory experience represents an object because that is its function. It informs about the environment because that is its function. ${ }^{8}$ I content that this functional character is all we need to ensure that phenomenal character of experiences is intentional. Considering that to be intentional means to be directed to an object and that the phenomenal character of experience has the function of informing about the environment, we can see that phenomenal experiences provide information related to the environment even when there is no object being perceived. ${ }^{9}$

\footnotetext{
${ }^{8}$ I do not deny that the phenomenal character of experiences can be involved in many other cognitive activities, serving other purposes. However, I think that their basic function, which is to inform about the environment explains why individuals have certain physical experiences when they are in certain physical states.

${ }^{9}$ I agree with Tye when he says that the phenomenal character of an experience is the complex of properties represented by the experience. However I do not agree with him when he affirms that he no longer believes that the phenomenal character is part of the content of a perceptual experience (CRANER, 2013, p.18).
} 
I am not saying that, in order to specify the perceptual relation, it is enough to say that the phenomenal character of experiences has the function of informing about the environment. The phenomenal character of accurate experiences not only has the function to inform about properties of the environment, but also informs us that the object is present, and that is part of the experience. However, if it is possible to misperceive the world, then the object of perceptual experience does not need to be veridical. The perceptual relation can be inaccurate without losing its relational character to an actual object. Hence, having a relation to an actual object is a condition in order for an experience to be a perceptual experience, but it is not a condition in order for an experience to be intentional. Although hallucinatory experiences are not relational in the same sense as perceptual experiences, because they are not related to actual objects, they are still intentional. This means that the phenomenal character of hallucinatory experiences represents properties of the environment. This relationship to the properties of the environment was established through causal relations between individuals and their environment through the evolutionary process of co-variation.

To explain these relations to the properties of the environment in cases of hallucinatory experiences, I think that it is necessary to resort to the concept of function, which relates to certain physical states that are responsible for the phenomenal properties that appear to the individual in the environment.

\section{Perceptual intentionalism and Physicism}

Therefore, I think that it is possible to reply to some objections that have been directed to the intentionalist approach of perception by accepting a physicalist view about perceptual experience. This view is committed to the thesis that the phenomenal character of experiences is either identical or supervenient to physical properties related to the neurophysiological states of the individual. ${ }^{10}$ If physicalism is accepted, it is plausible to view the phenomenal character of an experience as informing the individual about the environment because it is the function of experience to do that, and one important characteristic of a functional state is that it does not change or lose its function even when this function is not accomplished.

\footnotetext{
${ }^{10}$ In this article, I assume a physicalist view of the relation between phenomenal properties and physical properties, without specifying it explicitly. I believe that the problem of how consciousness emerges from the physical is a very hard problem, as David Chalmers has shown in many of his works, and it is not the subject of this article.
} 
In visual perception, the external object is the actual object that the individual is seeing, the object present in the experience, and the causal object that is responsible for the perceptual experience, but it is also possible to have a visual hallucination with the same phenomenal character. The potential absence of the object changes what these phenomenal properties effectively inform, but it cannot change what is their function to inform about the properties of the environment. ${ }^{11}$

I defend the functional view because it seems to me a reasonable way to explain why we have certain experiences when we are in a certain physical state. That fact can be explained by our evolutionary history, and not only by the development and the realization of individual capacities.

This is sufficient to affirm two important things. Firstly, the phenomenal character of experiences is part of the intentional content. It is related to the external world because the ability to be in such states cannot be separated from the environment, even in hallucinatory experiences. It is the function of these phenomenal states to inform about the world.

Secondly, veridical perceptual states have priority over non-veridical ones. This is a characteristic that Martin presents as being only proper to disjunctivism (MARTIN, 2002b, p. 401). If experiential states are functional states and evolved in order to inform about the world, these states aim accuracy; inaccuracy is possible, but it is not the function of a perceptual experience to inform about an object that is not what it represents. ${ }^{12}$ The priority of accuracy explains why individuals behave in the same way whether they are having a hallucinatory experience or an accurate experience, and it also explains why some of them form beliefs that are suitable to accurate experiences. The reason is that, in many cases, the phenomenal content alone is not sufficient to characterize hallucinatory states as hallucinatory.

Therefore, intentionalists can accommodate both theses:-the acceptance of the principle of common factor and the relational view of perception. They

\footnotetext{
${ }^{11}$ The approach that I am assuming regarding the concept of function aims to explain the function, clarifying why a trait or behavior is present in the living organism to which it belongs, performing a functional role. It sees the concept of function as normative and argues that it is only possible to understand the full meaning of a functional explanation when its normative character is recognized.

${ }^{12}$ The relation between evolution and veridical perception is a controversial subject. The question about whether or not evolution favors veridical perception does not have a simple answer. For instance, Burge (2010) thinks that evolution and veridical perception are completed independent of one another. I do not discuss this subject here, but, contrary to Burge, I assume that there is probably an important relation between veridical perception and having accurate information about the environment.
} 
can hold that all phenomenal experiences are about the properties of the environment, and that phenomenal experiences are perceptual experiences only when the individual is in direct relation to the external object, and when the content is a presentation of the object.

It could be countered that this argument is not sufficient to solve the difficulty that is presented to intentionalists because a perceptual experience is always a particular case of an experience, and the appeal to remote causes to ground the relation between the external properties of the world and the phenomenal properties of the experience is not useful in explaining how perceptual content is related to perceptual objects.

Since I accept that the presence of an object is a condition for considering an experience as perceptual, I am not only appealing to remote causes to explain perception. I am appealing them to explain why the experiences have an intentional phenomenal character, and to hold that it is related to the properties of the environment, even when there is no object.

In the same way that inaccurate perceptions are not independent from accurate ones, an accurate perception is not independent from the fact that biological evolution established a relation between certain types of physical state and certain types of external property. To consider a perceptual experience as inaccurate, we must at least realize that an alternative experience could be accurate. In the same way, to explain what happens when an individual perceives, we should understand that his ability to have this experience is not an isolated case. This explains why certain experiences involve the presentation of certain external properties and not others, and why intentionalists can assume that the phenomenal character of an experience represents properties of the environment, even when there is no actual object that is causing the experience.

\section{Conclusion}

Therefore, I think that intentionalists do not need to appeal to an intentional object that is understood as unreal and transcending intentional states in order to maintain an intentional view of perceptual experience. We need to understand that the phenomenal character of experiences as always representing properties of the environment because it is their function to do that. It is not necessary to abandon the "common factor principle", which says that hallucinatory, illusory, and veridical experiences sometimes can have 
the same phenomenal character, and claim that perceptual experiences give us direct information about the environment that is causing them. Instead, intentionalists can hold that the acceptance of the common factor principle coheres with the thesis that the phenomenal characters of experience are about the properties of the external world, even when there is no object. This is because they are intentional, and always intend to inform about the environment, even when they fail to do that accurately.

CHEDIAK, Karla. Intencionalismo perceptivo e o problema do objeto da percepção. Trans/form/ação, Marília, v. 39, n. 2, p. 87-100, Abr./Jun., 2016.

RESUMO: Este artigo visa a abordar algumas das dificuldades que o intencionalismo perceptivo enfrenta, ao especificar a natureza da experiência perceptiva e o objeto da percepçáo. Meu objetivo é mostrar que o intencionalista pode incorporar a tese associada ao disjuntivismo de que o objeto da percepção é parte da experiência perceptiva, sem abrir mão do princípio do fator comum. Eu defendo que, para fazer isso, é necessário recorrer ao conceito de função biológica e realizar uma revisão do conceito de objeto da percepção.

PALAVRAS-CHAVE: Intencionalismo perceptivo. Objeto intencional. Alucinação. Disjuntivismo. Função biológica.

\section{REFERENCES}

BURGE, T. Disjunctivism and perceptual psychology. Philosophical Topics, v. 33, n. 1, p. $1-78,2005$.

. Origins of objectivity. Oxford: Oxford University Press, 2010.

CHALMERS, D. The conscious mind. Oxford: Oxford University Press, 1996.

CRANE, T. Elements of mind: an introduction to the philosophy of mind. Oxford: Oxford University Press, 2001.

Is there a perceptual relation? In: GENDLER, T.; HOWTHORNE, J. Perceptual experience. Oxford: Oxford Univ. Press, 2006. p. 126-146.

Intentionalism. In: BECKERMANN, A.; McLAUGHLIN, B. Oxford handbook of mind. Oxford: Oxford University Press, 2007. p. 474-493.

. The objects of thought. Oxford: Oxford University Press, 2013.

DRETSKE, F. Naturalizing the mind. Cambridge: MIT Press, 1995.

HARMAN, G. The intrinsic quality of experience. Philosophical Perspectives, v. 4, p. 31-52, 1990. 
CHEDIAK, $\mathrm{K}$.

JACKSON, F. Perception: a representative theory. Cambridge: Cambridge University Press, 1977.

MARTIN, M. Particular thoughts \& singular thoughts. Royal Institute of Philosophy Supplement, v. 51, p. 173-214, 2002a. 2002b.

. The transparence of experience. Mind and Language, v. 17, n. 4, p. 376-425,

. Transparency, qualia realism and representationalism. Philosophical Studies, v. 70, n. 1 p. 39-57, 2014.

Recebido em 30/10/2015

Aceito em 05/01/2016 